\title{
Geometrical Properties of Hydrometeors during the Refreezing Process and Their Effects on Dual-Polarized Radar Signals
}

\author{
Nobuhiro Nagumo AND AhOro AdACHI \\ Meteorological Research Institute, Japan Meteorological Agency, Tsukuba, Japan \\ HIROSHI YAMAUCHI \\ Meteorological Research Institute, Japan Meteorological Agency, Tsukuba, and Japan Meteorological Agency, \\ Tokyo, Japan
}

(Manuscript received 7 August 2018, in final form 17 February 2019)

\begin{abstract}
This paper describes an observational study for the geometrical properties of hydrometeors during a refreezing process initiated by a winter storm in the northern Kanto Plain, Japan, on 29 January 2016, in which a subfreezing layer developed below a melting layer. The observations by using dual-polarization radar showed consistency between high values of differential reflectivity $Z_{\mathrm{DR}}$ signals in midair and icepellet reports at the surface. The high $Z_{\mathrm{DR}}$ was indicative of the sideways-oriented particles with a small axis ratio. The low $Z_{\mathrm{DR}}$ signals in midair corresponded with the reports of rain or rain/ice-pellet mixtures. Observations by using a two-dimensional video disdrometer (2DVD) near the ground showed different microphysics corresponding to high $Z_{\mathrm{DR}}$ and low $Z_{\mathrm{DR}}$ periods. The high $Z_{\mathrm{DR}}$ periods of 2DVD observations indicated that the hydrometeors exhibited dual modes of fall velocities, namely, fast-falling and slow-falling modes. The fast-falling particles were found to be deformed ice pellets with long sideways orientations that contributed to the high $Z_{\mathrm{DR}}$. The slow-falling particles were also deformed ice pellets but with a variety of orientations. This feature was rather close to that of general dry conditions of ice particles in the atmosphere. Meanwhile, the low $Z_{\mathrm{DR}}$ periods of 2DVD observations indicated that the hydrometeors exhibited a single mode of fall velocity close to the terminal velocity of raindrops, but with a more spherical shape compared to raindrops. Hence, it is suggested that the high $Z_{\mathrm{DR}}$ signal occurs during freezing between the initial stage of spherical ice forming and completely freezing stage of ice pellets with a variety of orientations.
\end{abstract}

\section{Introduction}

Ice pellets and freezing rain become potentially more hazardous with increases in their duration because such events can lead to the deposition of ice on roads, in-flight aircraft, and electric wires, which may cause serious accidents and major power outages (e.g., Ressler et al. 2012). Supercooled droplets freeze immediately upon contact with a surface at subfreezing temperatures, while ice pellets form when supercooled droplets freeze in the atmosphere (e.g., Brooks 1920; Crawford and Stewart 1995; Stewart and Crawford 1995).

The process of freezing of supercooled liquid particles has been studied in the laboratory and the field from the viewpoints of influence of ice nucleus (e.g., Edwards and

Corresponding author: Nobuhiro Nagumo, nagumo@mri-jma.go.jp
Evans 1971; Joseph and Will 2015), phase transition to ice, subsequent deformation of particles (Dorsey 1948; Blanchard 1957; Takahashi and Yamashita 1970; Gokhale and Lewinter 1971; Takahashi 1975; Gibson and Stewart 2007; Gibson et al. 2009), and particle motions (Spengler and Gokhale 1972; Bringi and Chandrasekar 2001; Anderson et al. 2011; Ryzhkov et al. 2011).

However, there is only a fragmentary understanding of the spatiotemporal characteristics of the actual freezing process in the atmosphere. Nagumo and Fujiyoshi (2015) found that there were dual modes of falling velocities of ice pellets at the ground level and suggested that wet ice pellets and dry, low density ice pellets coexisted at the same time. It was also suggested that many dry, low density ice pellets occurred almost simultaneously within a narrow range of altitudes in subfreezing layer. However, there are no microphysical verification data for the particles aloft. 


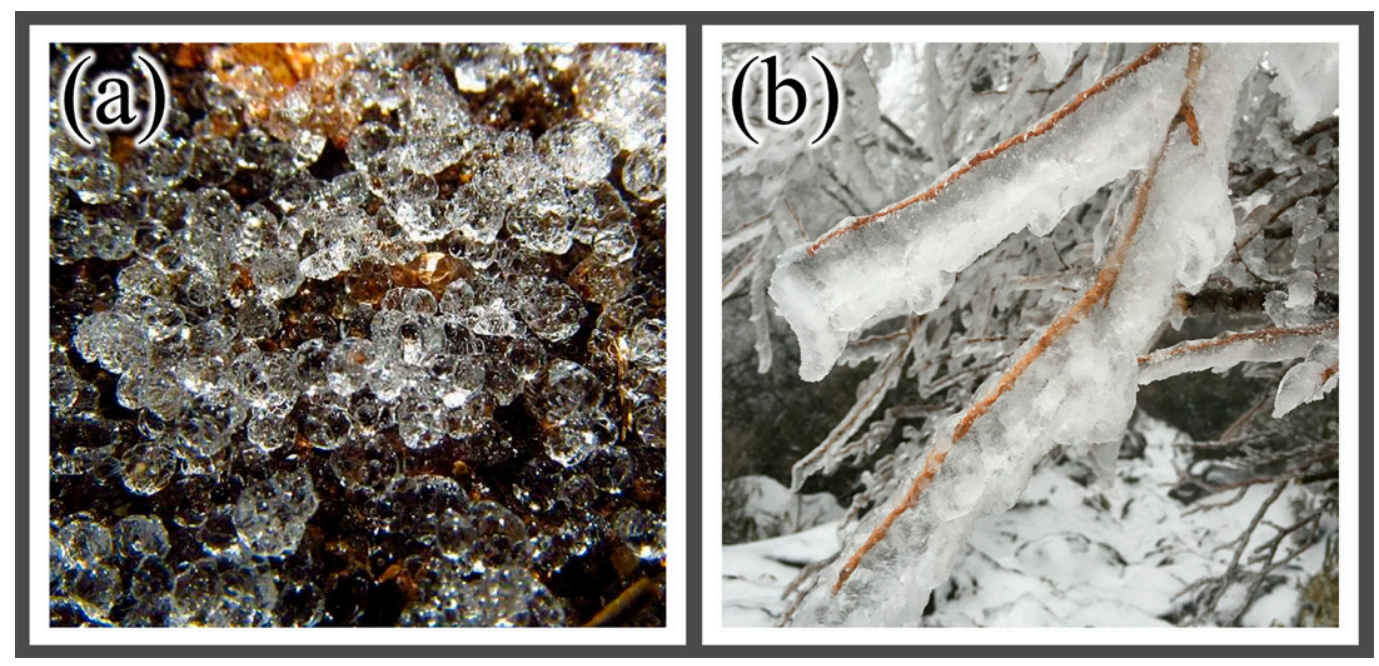

FIG. 1. (a) Ice pellets photographed near the MRI (4 km north) at around 2400 JST 29 Jan 2016. The maximum size of ice pellets is roughly $2 \mathrm{~mm}$. (b) Branches covered by freezing rain at $770 \mathrm{~m}$ above mean sea level (MSL) of Mt. Tsukuba (elevation: $877 \mathrm{~m}$ ), where the environment experienced subfreezing conditions for a while. The maximum thickness of branches is roughly $5 \mathrm{~mm}$. (The photograph of the branch was taken on $30 \mathrm{Jan} 2016$.)

A dual-polarization radar is one of the instruments that can observe precipitation particles in the upper atmosphere and possibly discriminate among particle types (e.g., Thompson et al. 2014). Dual-polarization radars that transmit and receive linearly orthogonal polarizations (i.e., horizontal and vertical) simultaneously provide the following observables: radar reflectivity factor at horizontal polarization $Z_{\mathrm{H}}$, vertical polarization $Z_{\mathrm{V}}$, differential reflectivity $Z_{\mathrm{DR}}$, copolar correlation coefficient $\rho_{\mathrm{hv}}$, differential propagation phase shift $\Phi_{\mathrm{DP}}$, and one-half of its range derivative, the specific differential phase $K_{\mathrm{DP}}$. The $Z_{\mathrm{DR}}$ value represents the reflectivity weighted mean axis ratio of all the drops in the pulse volume as $Z_{\mathrm{DR}}=10 \log _{10}\left(Z_{\mathrm{H}} / Z_{\mathrm{V}}\right)$, and higher $Z_{\mathrm{DR}}$ values generally represent an increase of particles with a lower axis ratio. The height of the $\rho_{\mathrm{hv}}$ value suggests the uniformity of particles in the pulse volume and can help to identify the presence of mixed-phase precipitation in winter storms. Kumjian et al. (2013) investigated dualpolarization signature associated with freezing raindrops (i.e., ice pellets or sleet), namely the "refreezing signature," seen as a local increase (decrease) in $Z_{\mathrm{DR}}\left(\rho_{\mathrm{hv}}\right)$ below a bright band within the subfreezing layer. The development of discrimination techniques using dualpolarization radar could lead to a promising solution for ice-pellet detection over a wide range of atmospheric conditions. However, the mechanism by which a high $Z_{\mathrm{DR}}$ value gives rise to such a signature is still uncertain; presently, it has been deduced through hypothetical simulations to entail smaller melted raindrops that freeze ahead of the larger ones, and then, the signals of larger raindrops become more pronounced. This hypothesis is inconsistent with previous experiments that found that larger particles are likely to initiate freezing (Bigg 1953; Pruppacher and Klett 1997). An appropriate understanding of the freezing mechanism and underlying microphysics is an essential step toward the development of advanced precipitation monitoring techniques for dangerous winter storms.

An ice-pellet event occurred on 29 January 2016, in the north Kanto Plain, Japan, together with freezing rain over the vicinity of the mountains (Figs. 1a and 1b). Ice pellets fell for an extended period in the Kanto Plain. Freezing rain in the mountainous area resulted in the fourth-worst forest damage extent with costs amounting to over $\$ 6$ million (U.S. dollars) in the Nagano prefecture alone; in addition, there were human injuries, damage to houses, electrical outages ( 2400 homes), water outages ( 40 homes), isolated settlements ( 320 people), and blocked highways. We observed the dual-polarization signals of this ice-pellet/freezing-rain event by using the Meteorological Research Institute (MRI) advanced C-band solid-state polarization radar (MACS-POL radar) mounted on top of the MRI building in Tsukuba, Japan (Adachi et al. 2013), and the microphysical properties were observed by using the two-dimensional video disdrometer (2DVD; Schönhuber et al. 2007, 2008) installed at the MRI field.

In this paper, we present and discuss new findings regarding the microphysical properties of ice pellets in relation to their geometries and examine the reason for the higher values of $Z_{\mathrm{DR}}$ signals corresponding to freezing processes through data comparisons between the MACS-POL radar and 2DVD. Finally, we summarize 

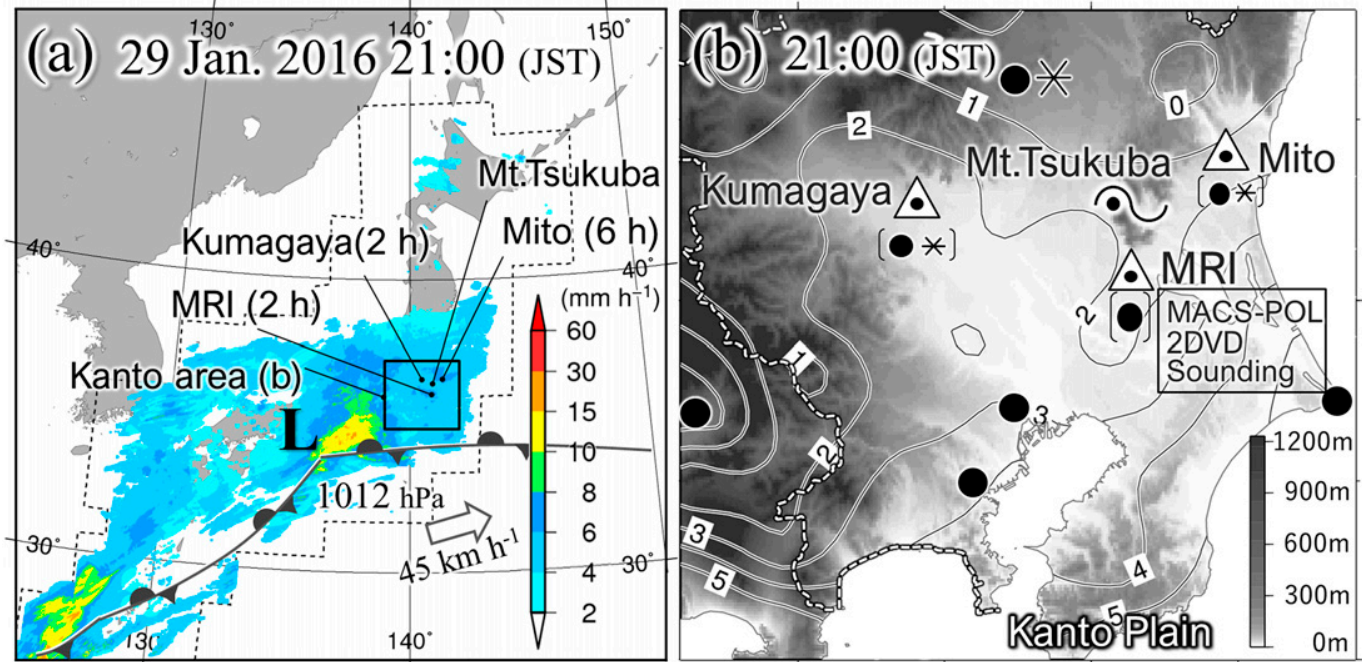

FIG. 2. (a) The precipitation rates at 2100 JST derived from the JMA radar and ice-pellet periods at the observatories. (b) The surface temperature around the Kanto Plain at 2100 JST, topography (shaded), and the observatory reports on 29 Jan 2016 (triangles with dots: ice pellets; waves with dots: freezing rain; black dots: rain; six pointed stars: snow). The hydrometeor types in parentheses represent the main precipitation types for the day.

the geometrical changes during the transition from raindrops to frozen ice pellets.

\section{Methodology}

\section{a. Synoptic-scale environment}

Precipitation associated with a low pressure system with a frontal structure was observed at approximately 0900 Japan standard time (JST) (JST = UTC $+9 \mathrm{~h}$ ) on 29 January 2016, in the Kanto area, Japan. The Kanto area was covered with precipitation at 2100 JST (Fig. 2a). The precipitation rate was less than $4 \mathrm{~mm} \mathrm{~h}^{-1}$ in the Kanto area. The precipitation stopped the following morning. Ice pellets were reported at the Mito observatory $(6 \mathrm{~h})$ and the Kumagaya observatory ( $2 \mathrm{~h}$ ) of the Japan Meteorological Agency (JMA), and pellets were collected at the MRI $(2 \mathrm{~h})$ (Fig. 2b). These ice pellets were reported in a humid near-surface environment as a result of the long-term precipitation (relative humidity: $>90 \%$ ). The surface air temperature of these areas was below $3^{\circ} \mathrm{C}$ (slightly lower in terms of the wet-bulb temperature) and within the range for the general temperature of ice-pellet occurrence (Cortinas et al. 2004). Evidence of freezing rain was widely confirmed at altitudes higher than $400 \mathrm{~m}$ on Mt. Tsukuba, which is located $10 \mathrm{~km}$ north of the MRI, $20 \mathrm{~km}$ west of Mito, and $60 \mathrm{~km}$ east of Kumagaya. The operational sounding of the JMA at the MRI field (No. 47646) showed a subfreezing layer (400-2000 m) with a northeast wind below a melting layer (2000$2500 \mathrm{~m}$ ) with a southwest wind at 2100 JST (Fig. 3). The minimum temperature at $2100 \mathrm{JST}$ was $-3.3^{\circ} \mathrm{C}$ in the subfreezing layer. This was a favorable environment for ice pellets at the surface and freezing rain within the altitude of subfreezing layer.

The surface air temperature at the area of ice pellets did not change much during the event. The reported time and shooting time of ice pellets was within $0^{\circ}-3^{\circ} \mathrm{C}$ (Fig. 4a). The altitude near the top of Mt. Tsukuba (elevation: $877 \mathrm{~m}$ ) also had favorable temperatures for freezing within the $-2^{\circ}$ to $-4^{\circ} \mathrm{C}$ range (Fig. 4b). Given the temperature difference between soundings and Mt. Tsukuba at $870 \mathrm{~m}\left(\sim 1.5^{\circ} \mathrm{C}\right)$, the minimum air temperature in the subfreezing layer over the MRI, which advected from the northwest, may have been lower than $-3.3^{\circ} \mathrm{C}$. There are several studies of ice formation at warm temperatures of about $-4^{\circ} \mathrm{C}$ (Mossop et al. 1968; Stewart and Crawford 1995; Sassen et al. 2003).

\section{b. Observational designs of the MACS-POL radar and the $2 D V D$}

The analysis was conducted during 1500-2400 JST 29 January 2016, from the standpoint of the detection of ice pellets at the warm surface $\left(<3^{\circ} \mathrm{C}\right)$.

The relations between hydrometeor types at the observatories and dual-polarized signals were examined by using the MACS-POL radar data. The operating parameters are described in Table 1 . The spatiotemporal characteristics of the plan position indicator (PPI) for the $1.5^{\circ}$ elevations with the $Z_{\mathrm{H}}, Z_{\mathrm{DR}}$, and $\rho_{\mathrm{hv}}$ data were examined. The $Z_{\mathrm{DR}}$ signals near the 


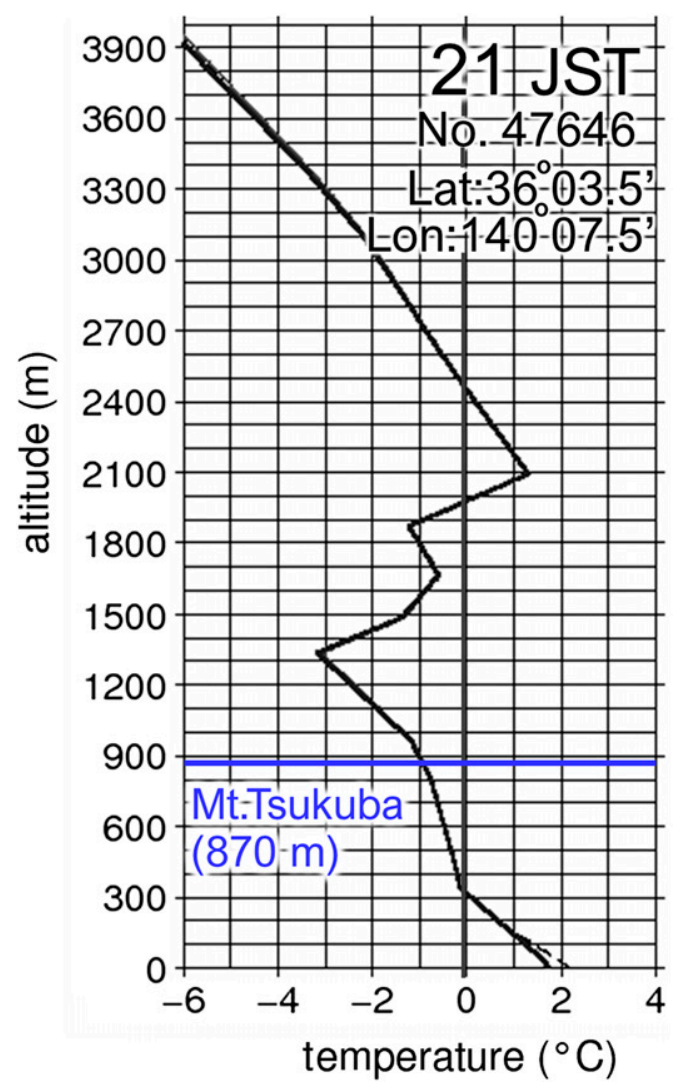

FIG. 3. Vertical profile of temperature at 2100 JST at the MRI field (solid: wet-bulb temperature; dashed: dry-bulb temperature). The observed period: 2030:00-2154:12 JST. Blue line indicates the top of Mt. Tsukuba.

ground (at $0.5^{\circ}$ and $1.0^{\circ}$ elevations) were also compared with the observatory reports. In this paper, $Z_{\mathrm{DR}}$ values over $0.5 \mathrm{~dB}$ in terms of the mean and $0.4 \mathrm{~dB}$ in terms of the standard deviation were treated as high values. The $\rho_{\text {hv }}$ values lower than 0.95 were treated as low values. Radar values at the Mito observatory ( $45 \mathrm{~km}$ northeast of the MRI) indicate $\sim 800 \mathrm{~m}$ above ground level (AGL) signals for a radar angle of $1.0^{\circ}$ elevation, and those at Kumagaya ( $60 \mathrm{~km}$ WNW of the MRI) indicate $\sim 500 \mathrm{~m}$ AGL signals for a radar angle of $0.5^{\circ}$ elevation; these were probably at the location of the bottom of the subfreezing layer (Figs. 3 and 4b). These values represent the $4 \mathrm{~km}^{2}$ mean and deviation over the observatories.

The microphysics of hydrometeors in terms of the particle shape, fall velocity, and axis ratio were compared between different $Z_{\mathrm{DR}}$ signals and with previous microphysical findings of hydrometeors. The 2DVD provided the particle equivolumetric diameter (hereafter, diameter), fall velocity, and axis ratio from bidirectional images within the $10 \mathrm{~cm} \times 10 \mathrm{~cm}$ observable area. The particle shapes with a diameter
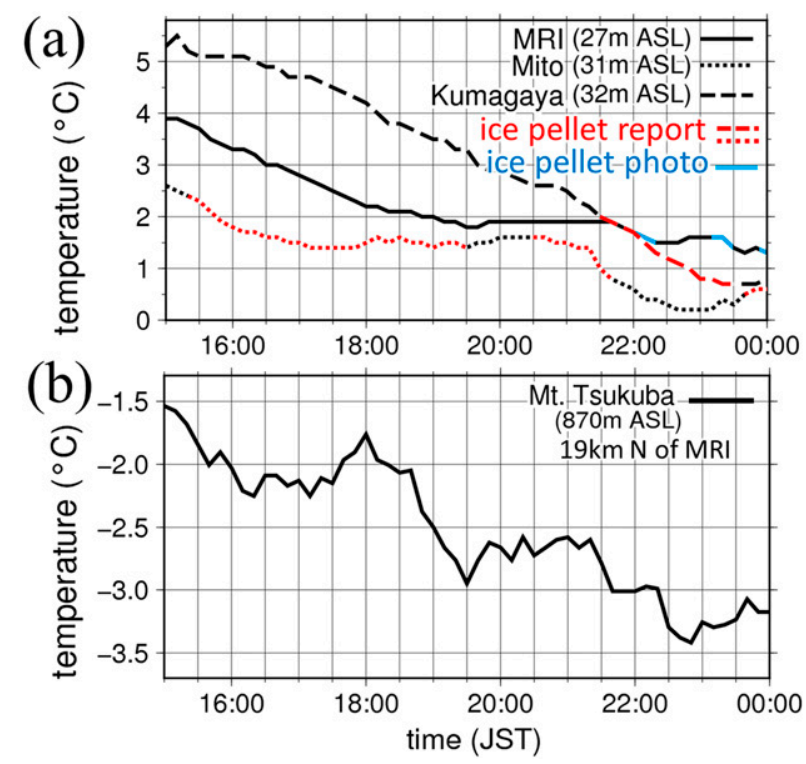

FIG. 4. (a) The surface temperatures at the MRI, Mito, and Kumagaya observatory and (b) the temperature at $870 \mathrm{~m}$ MSL of Mt. Tsukuba. Red colors indicate the periods of ice-pellet reports. Blue colors indicate the shooting time of ice pellets around the MRI by some researchers.

over $1.5 \mathrm{~mm}$ were visually classified in the same manner as that described in Nagumo and Fujiyoshi (2015). The fall velocity was calculated from the time lag of bidirectional detections due to a slight vertical gap. The axis ratio was calculated from the horizontal maximum length $a$ and vertical maximum length $b$ as $b / a$ from each image. The resolution of the measured images was better than $0.19 \mathrm{~mm}$, and the variation of error for the fall velocity measurements was better than $4 \%$ for velocities below $10 \mathrm{~m} \mathrm{~s}^{-1}$ (Schönhuber et al. 2007). There were no erroneous images of particle within the range over $1.5 \mathrm{~mm}$ for classifications of particle shape.

\section{Analyses of geometrical characteristics}

\section{a. The relation between dual-polarization signals and observatory reports}

The radar reflectivity factor $Z_{\mathrm{H}}$ presented strong echoes with $Z_{\mathrm{H}}$ exceeding $25 \mathrm{~dB} Z$ in lower altitudes (close to the radar) and weak echoes in higher altitudes, which are bounded by second auxiliary circles indicating a distance of $100 \mathrm{~km}$ in Figs. 5a-d. This was the common characteristic during the event from rain to ice pellets at the MRI field. The extent of strong echoes was suggested by the bright band of the melting layer over a wide range because the distance of $60-100 \mathrm{~km}$ from the radar for the $1.5^{\circ}$ elevation angle corresponded 
TABLE 1. Operating characteristics of the MRI advanced C-band solid-state polarization radar (MACS-POL).

\begin{tabular}{ll}
\hline \hline Frequency & $5370 \mathrm{MHz}(\mathrm{C}$ band $)$ \\
Occupied bandwidth & $<4.5 \mathrm{MHz}$ \\
Peak power & $3.5 \mathrm{~kW}$ (for each channel, simultaneous transmission) \\
PPI elevation (Elv.) & $0.5^{\circ}, 1.0^{\circ}, 1.5^{\circ}, 2.1^{\circ}, 2.8^{\circ}, 3.6^{\circ}, 4.8^{\circ}, 6.2^{\circ}, 8.0^{\circ}, 10.4^{\circ}, 14.0^{\circ}, 18.0^{\circ}$ \\
Antenna diameter & $4 \mathrm{~m}$ of parabolic dish (beamwidth $\left.0.7^{\circ}\right)$ \\
Range gate spacing & $150 \mathrm{~m}$ \\
Observation parameter & $Z_{\mathrm{H}}, Z_{\mathrm{V}}, Z_{\mathrm{DR}}$, radial velocity $V, \rho_{\mathrm{hv}}$, and $\Phi_{\mathrm{DP}}$ \\
Manufacture & TOSHIBA \\
Transmitter & GaAs Power FET \\
Pulse compression & Linear FM chirp for long-pulse observations \\
Signal minimum & $<-110 \mathrm{dBm}$ \\
& \\
Pulse length & Time: $0900-2221$ and $2343-2359 \mathrm{JST}$ \\
Antenna speed & $1 \mu \mathrm{s}(\mathrm{range}<20 \mathrm{~km})$ and $129 \mu \mathrm{s}(\geq 20 \mathrm{~km})$ for Elv. $<8^{\circ}$ \\
Pulse repetition frequency & $/ 1 \mu \mathrm{s} \mathrm{(range}<10 \mathrm{~km})$ and $67 \mu \mathrm{s}(>10 \mathrm{~km})$ for Elv. $\geq 8^{\circ}$ \\
& $4.0 \mathrm{rpm}\left(\right.$ Elv. $\left.<8^{\circ}\right) / 5.5 \mathrm{rpm}\left(\right.$ Elv. $\left.\geq 8^{\circ}\right)$ \\
Pulse length & $624 / 780 \mathrm{~Hz}\left(\right.$ Elv. $\left.<8^{\circ}\right)$ and $888 / 1110 \mathrm{~Hz}\left(\right.$ Elv. $\left.\geq 8^{\circ}\right)$ \\
Antenna speed & \\
Pulse repetition frequency & Time: $2222-2342 \mathrm{JST}$ \\
\hline
\end{tabular}

to the altitude of temperature over $0^{\circ} \mathrm{C}(1.6-2.6 \mathrm{~km})$ in Fig. 3, but the bottom of strong echoes was poorly defined and seemed to diffuse into the subfreezing layer. However, the differential reflectivity $Z_{\mathrm{DR}}$ presented a clear band with high $Z_{\mathrm{DR}}$ values over $0.5 \mathrm{~dB}$ on average with some variations (Figs. 5e-h). The south side showed an arcuate shape, and the north side showed a single or double nonarcuate shape. The $\rho_{\text {hv }}$ values that corresponded to the high values of $Z_{\mathrm{DR}}$ consisted of low values less than 0.95 (Figs. $5 \mathrm{i}-1$ ). The arcuate parts on the south side corresponded to the altitude of melting layers from soundings at $2100 \mathrm{JST}$, as indicated in previous studies (e.g., Zrnić et al. 1993; Brandes and Ikeda 2004; Baldini and Gorgucchi 2006; Kumjian et al. 2013). The inner radius of the arcuate part was $\sim 60 \mathrm{~km}$ at $1.5^{\circ}$ of the PPI (Figs. 5e-h and 5i-l). The data suggested that the most arcuate parts showed complete melting at similar altitudes.

The nonarcuate parts with higher values of $Z_{\mathrm{DR}}$ and lower values of $\rho_{\mathrm{hv}}$ were located $50 \mathrm{~km}$ away from the MRI at first until 2100 JST. This signal was located over the Mito observatory for a while (Figs. 5e and 5i). This signal subsequently moved south and was located over the MRI and over the Kumagaya observatory at 2124-2240 JST (Figs. 5f and 5j). Next, the nonarcuate parts gradually showed two signals in one scanning line of the radar from 2240 (Figs. $5 \mathrm{~g}$ and $5 \mathrm{k}$ ) to 2330 JST(Figs. 5h and 5l). The inner part of the nonarcuate shape passed over the MRI and Kumagaya again at around 2330 JST.

Figure 6 shows the vertical cross section of the smoothed radar variables in the north direction $\left(340^{\circ}\right)$ at around 2330 JST constructed by all PPI sets at the time of double nonarcuate signals (A-B in Figs. 5d, 5h, and 5l) and the time of ice pellets around the MRI (Fig. 1a). The vertical cross section displayed two parts for the high $Z_{\mathrm{DR}}$ and the low $\rho_{\mathrm{hv}}$ separately within the distance of $10 \mathrm{~km}$ of the MRI. The higher altitude of signals with high $Z_{\mathrm{DR}}$ values and low $\rho_{\mathrm{hv}}$ values $(1500-2000 \mathrm{~m})$ was close to the brightband signal of $Z_{\mathrm{H}}$; however, the peak of both signals was slightly lower than the altitude of the $Z_{\mathrm{H}}$ brightband peak. The lower altitude of both signals was probably in the subfreezing layer (Figs. 3 and $4 \mathrm{~b}$ ). The peaks of $Z_{\mathrm{DR}}$ signals $(300-800 \mathrm{~m})$ were slightly higher than those of $\rho_{\text {hv }}$ signals $(0-700 \mathrm{~m})$. These findings are consistent with some of the ice-pellet events reported in Kumjian et al. (2013).

The high value of the mean $Z_{\mathrm{DR}}$ with a high standard deviation over the observatories in the nonarcuate area showed good agreement with the ice-pellet reports (black arrow periods in Fig. 7). The other periods were mainly reported as rain or rain/ice-pellet mixtures at the south location of the nonarcuate area and snow or partially snow at the north location of the nonarcuate area. The ice-pellet periods with double nonarcuate signals represented the refreezing environment from completely or almost melted particles. Whereas, other icepellet reports with single nonarcuate signals (e.g., A-C and $\mathrm{A}-\mathrm{C}^{\prime}$ in Figs. $3 \mathrm{j}$ and 31 ) were considered to be from the freezing of semimelted snowflakes, because the high $Z_{\mathrm{DR}}$ values of the melting layer signal and that of the subfreezing layer signal had been connected linearly. Besides, freezing rain was also observed during the event (Fig. 1b). The periods with the double nonarcuate 

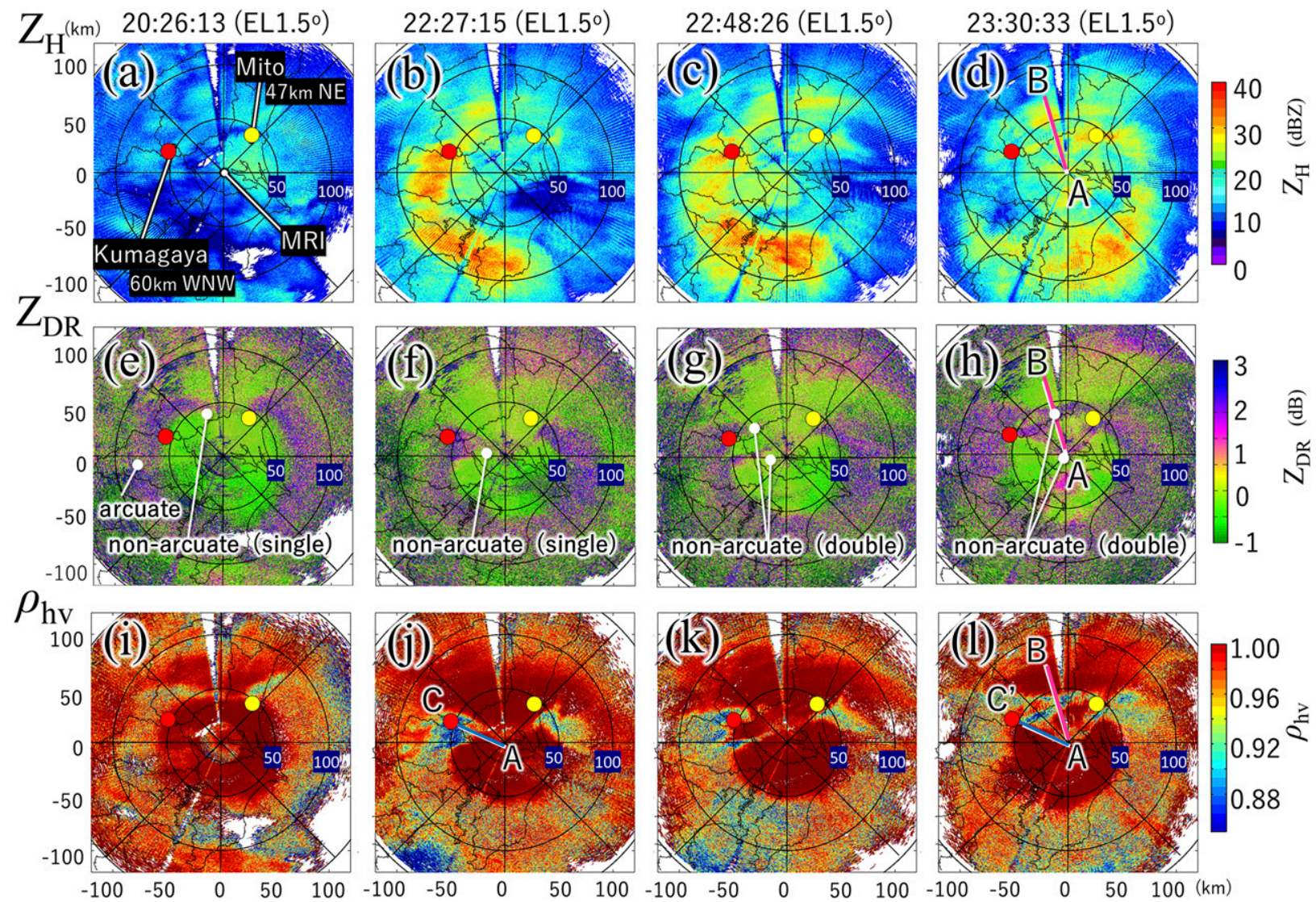

FIG. 5. The time series of the plan position indicator (PPI) results for the MACS-POL radar along the $1.5^{\circ}$ elevation: (a)-(d) The radar reflectivity factor at horizontal polarization $Z_{\mathrm{H}},(\mathrm{e})-(\mathrm{h})$ the differential reflectivity factor $Z_{\mathrm{DR}}$, and (i)-(1) the copolar correlation coefficient $\rho_{\mathrm{hv}}$. The center of the PPI is the location of the radar. The rings represent $50-\mathrm{km}$ intervals from the radar. Yellow dots indicate the location of the Mito observatory, and red dots indicate the location of the Kumagaya observatory.

parts of high $Z_{\mathrm{DR}}$ (low $\rho_{\mathrm{hv}}$ ) were considered to have a partial freezing rain layer in the region between the high $Z_{\mathrm{DR}}\left(\right.$ low $\rho_{\mathrm{hv}}$ ) values in the subfreezing layer.

Meanwhile, there were also periods of ice-pellet/rain mixture reports within the low mean $Z_{\mathrm{DR}}$ region with its low standard deviation (e.g., 1700-1930 and 2030-2110 JST in Figs. 7a,b). This feature is discussed in section 4 in terms of microphysics.

\section{b. Ground-based microphysics}

Figures $8 \mathrm{a}-\mathrm{d}$ show the relations between the diameter and fall velocity of the hydrometeors derived by using the 2DVD data at the MRI corresponding to the situations in Fig. 5, which were broken down by the periods of high $Z_{\mathrm{DR}}$ and low $Z_{\mathrm{DR}}$ at the MRI. The fall velocities in Figs. $8 \mathrm{~b}$ and $8 \mathrm{~d}$, which are the periods of high $Z_{\mathrm{DR}}$ (Figs. 5f and 5h), showed a bimodal distribution of falling velocities (fast- and slow-falling) consistent with the previous study of Nagumo and Fujiyoshi (2015). The fast-falling group was close to the terminal velocity of raindrops. The other was close to that of the dry, low density ice particles. The fall velocities in Figs. $8 \mathrm{a}$ and $8 \mathrm{c}$, which are the periods of low $Z_{\mathrm{DR}}$ (Figs. $5 \mathrm{e}$ and $5 \mathrm{~g}$ ), showed one group of fall velocities close to that of raindrops. Figures $8 \mathrm{e}-\mathrm{h}$ show the probability distributions of axis ratios corresponding to Figs. 8a-d. The hydrometeors in the high $Z_{\mathrm{DR}}$ periods had decreasing axis ratios with increasing diameters (Figs. $8 \mathrm{f}$ and $8 \mathrm{~h}$ ). This is rather similar to the features of raindrops (e.g., Pruppacher and Beard 1970; Green 1975; Poiares Baptista 1992; Thurai and Bringi 2005). On the other hand, the hydrometeors in the low $Z_{\mathrm{DR}}$ periods (Figs. 5e and $5 \mathrm{~g}$ ) had a distribution around the axis ratio 1 (Figs. $8 \mathrm{e}$ and $8 \mathrm{~g}$ ), although the observatory report under low $Z_{\mathrm{DR}}$ included rain (Fig. 7).

Figure 9 depicts representative hydrometeor silhouettes and their microphysical data (diameter, fall velocity, and axis ratio) during this event. Table 2 shows the details for the number and frequency of each hydrometeor silhouette for large diameters over $1.5 \mathrm{~mm}$. The shape of hydrometeors within the periods of high $Z_{\mathrm{DR}}$ showed deformed outlines, which were suggestive of bulged shapes in both the fast- and slow-falling groups 

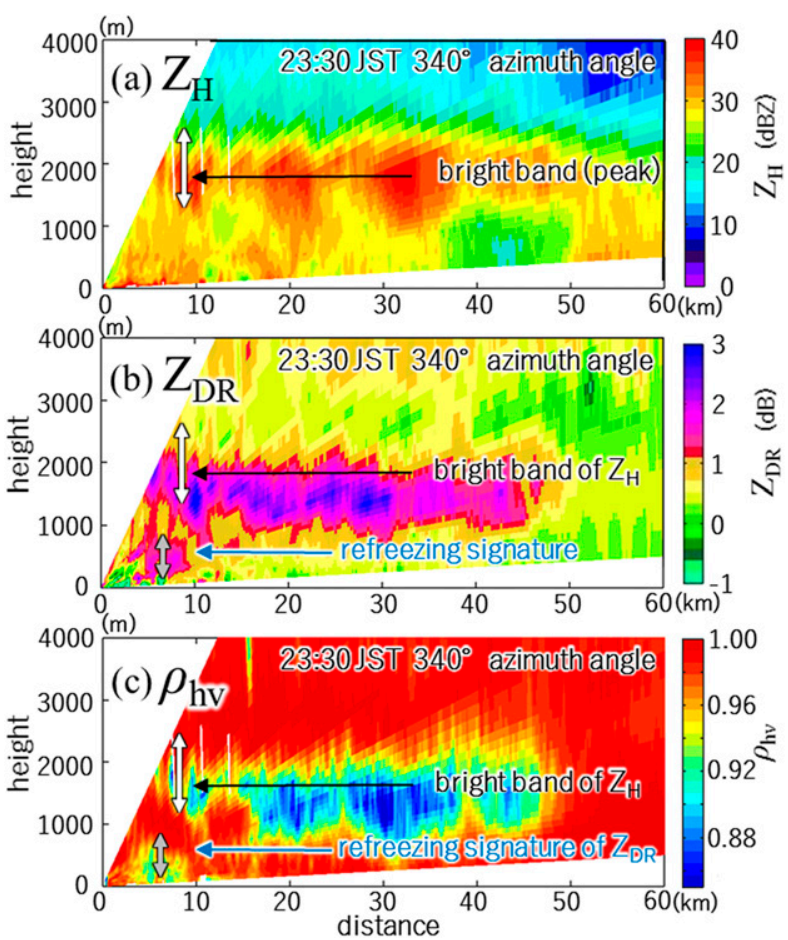

FIG. 6. Cross sections of the MACS-POL radar at 2330 JST by all the PPI sets along $340^{\circ}$ lines A-B in Figs. $5 \mathrm{~d}$, 5h, and 5l: (a) radar reflectivity factor at horizontal polarization $Z_{\mathrm{H}}$, (b) differential reflectivity factor $Z_{\mathrm{DR}}$, and (c) copolar correlation coefficient $\rho_{\mathrm{hv}}$. These data were interpolated between each elevation after averaging in the azimuth by three bins. White arrows represent the thickness of the bright band of $Z_{\mathrm{H}}$, and gray arrows represent the thickness of the refreezing signature of $Z_{\mathrm{DR}}$.

(Figs. 9a and 9b). A total of $92 \%$ of the bulged particles were collected in the high $Z_{\mathrm{DR}}$ periods, and higher frequencies were encountered in the slow-falling group. These silhouettes are different from those of raindroplike particles with a round top and flat bottom as shown in Figs. 9a and 9c. The hydrometeors with a fracturedlike outline were mostly ( $83 \%$ ) found in the slow-falling group (Fig. 9b). The nearly spherical particles, which seem to be the intermediate deformation from spherical to bulged shape, were collected more often in the fastfalling group. The hydrometeors within the low $Z_{\mathrm{DR}}$ periods had much smaller distortions (i.e., these were rather spherical; Fig. 9c). These major categories were common for each $Z_{\mathrm{DR}}$ period (high/low) and fall velocity group (fast/slow) when these occurrence periods were divided into time (Table 2). The frequency of raindrop-like particles was small overall $(<12 \%)$. Since the total particle classification was also similar to the findings for another ice-pellet event (Table 3), it is likely that these results were not random occurrences. As examples, the major category in the fast-falling group included bulged and nearly spherical particles, while that in the slow-falling group included bulged and fractured ones.

Figure 10 summarizes the $Z_{\mathrm{DR}}$ signals with geometrical characteristics. The high $Z_{\mathrm{DR}}$ periods, which match with ice-pellet reporting criteria of other observatories, showed the two falling velocity groups and descriptive shapes of high $Z_{\mathrm{DR}}$ (Figs. 10a and 10b), although the major geometries were slightly different between the fastand slow-falling groups (Fig. 10c). On the other hand, the low $Z_{\mathrm{DR}}$ periods, which match with the reports of rain or rain/ice-pellet mixture criteria at other observatories, showed one falling velocity group close to the raindrop terminal velocity and descriptive shapes of low $Z_{\mathrm{DR}}$. These findings contradict the conventional recognitions of dual-polarization characteristics in which the $Z_{\mathrm{DR}}$ of ice particles is generally lower than that of raindrops (e.g., Höller et al. 1994). In addition, the axis ratio $\sim 1$ with spherical shapes also contrast with raindrop axis ratio. In regard to the composition of particles in low $Z_{\mathrm{DR}}$ periods, it is unclear whether liquid or solid was present because the 2DVD images were silhouettes. In the next section, we discuss the relations between microphysics and increasing (decreasing) $Z_{\mathrm{DR}}$ values to help fill the gap between observed features during the freezing period and conventional ideas.

\section{Discussion}

\section{a. Validation of statistical fall orientations during times of enhanced $Z_{\mathrm{DR}}$}

The reasons for the increases in $Z_{\mathrm{DR}}$ in the subfreezing layer were investigated with the two fall velocity groups of particles by focusing on the diameter-axis ratio relations.

Figure 11 shows the diameter-axis ratio relations with their probability distributions, means, and standard deviations broken down by the fall velocity and $Z_{\mathrm{DR}}$ category. A dependence of the axis ratio on the diameter was found only in the fast-falling group during the high $Z_{\mathrm{DR}}$ period (Figs. 11a and 11d) and not in the slowfalling group (Figs. 11b and 11e). The axis ratio in the slow-falling group was approximately 1 with broad variations, or slightly higher than 1 . This is rather in line with conventional recognitions of ice particles regardless of particle size and wet/dry conditions (e.g., Höller et al. 1994). At the other times, the hydrometeor axis ratios during the low $Z_{\mathrm{DR}}$ period showed no diameter dependency with narrow variations (Figs. 11c and 11f). These differences suggest that the high $Z_{\mathrm{DR}}$, that is the refreezing signature, was caused by the presence of a majority of sideways-oriented particles with a small axis ratio in the fast-falling group. The long sideways 

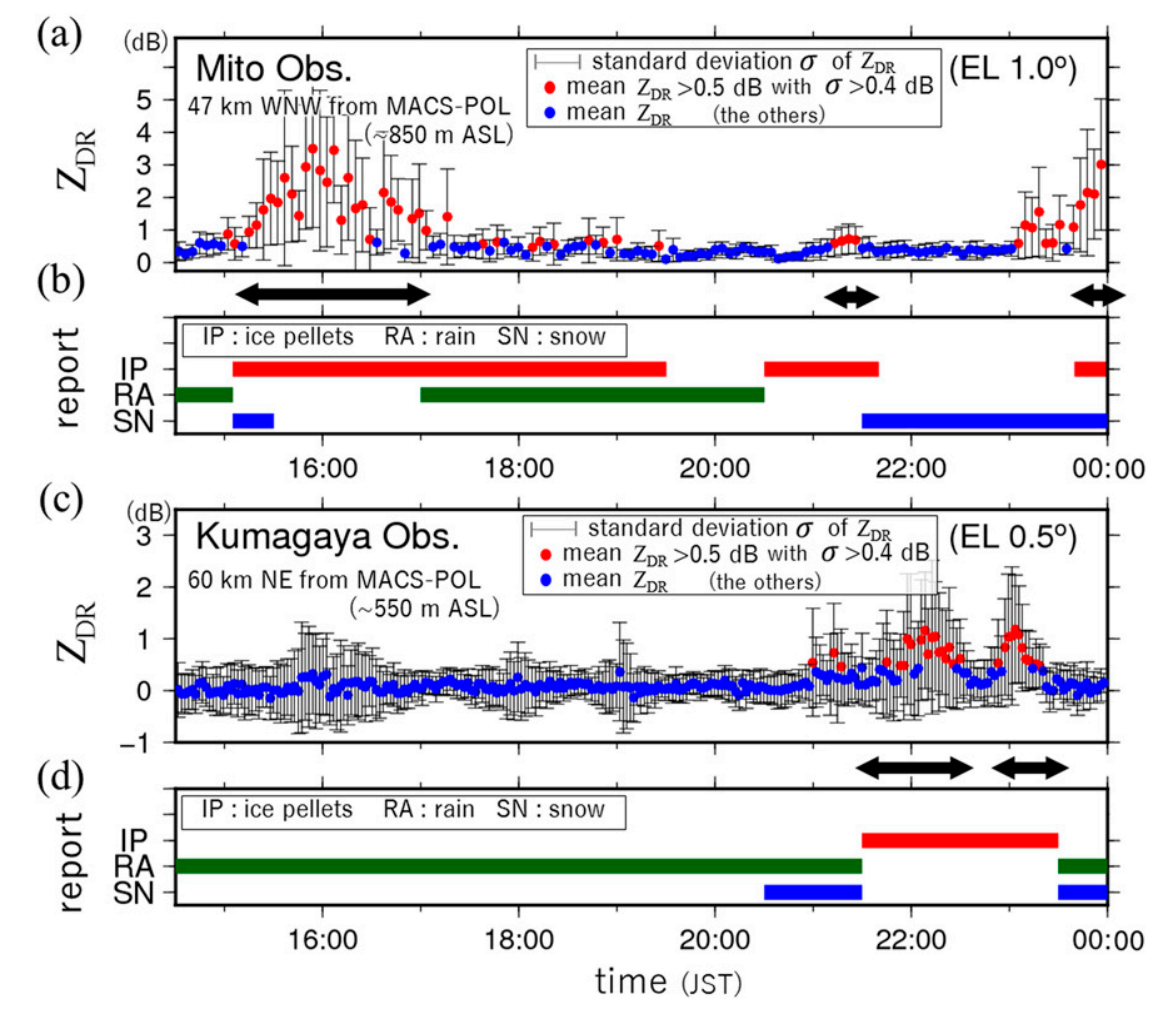

FIG. 7. Time series of the mean $Z_{\mathrm{DR}}$, standard deviation of $Z_{\mathrm{DR}}$, and hydrometeor types over the observatories: (a) Mito observatory $Z_{\mathrm{DR}}$, (b) Mito observatory hydrometeor report, (c) Kumagaya observatory $Z_{\mathrm{DR}}$, and (d) Kumagaya observatory hydrometeor report. The black arrows indicate the match time between the high mean $Z_{\mathrm{DR}}$ (red dot) and visual reports of ice pellets at observatories (red bar).

orientation is likely to occur under conditions with a low Reynolds number $(\mathrm{Re} \equiv d V / v)$. Here, $d$ is a diameter, $V$ is a fall velocity, and $v$ is a kinematic viscosity coefficient. According to List and Schemenauer (1971), the solid particles with a teardrop shape, similar to the bulged ice pellets in Fig. 9, take on stable long sideways orientations under low $\operatorname{Re}(<\sim 500-600)$ conditions. Meanwhile, it has been confirmed that the main particle behavior changes to a tumbling motion at $\operatorname{Re}>\sim 700$. This teardrop feature is applicable to the fast-falling group of particles. The threshold size of stable orientations was $\sim 1.5 \mathrm{~mm}$ in the case of the fast-falling group, assuming $0^{\circ} \mathrm{C}$ for $v$, as shown in Fig. 12 (red dots). The probability distribution of the fast-falling group showed gradual increases of variation in axis ratio for $1.5 \mathrm{~mm}$ and greater (Fig. 11a). The standard deviations also increased in the $>1.5$-mm range (Fig. 11d); although, the mean axis ratio still showed features of longer sidewaysoriented particles with increasing diameters within the collected size. Hence, deformed hydrometeors like nearly spherical and bulged ice pellets, which were the main geometrical shapes in the fast-falling group, can be considered to have been the cause of the high $Z_{\mathrm{DR}}$.
Then, the deviation of large particle orientations can be considered to have contributed to the high standard deviation of $Z_{\mathrm{DR}}$. Meanwhile, the probability distributions of axis ratios in the slow-falling group suggested that there were a variety of fall orientations in the deformed particles (Fig. 11b), and the mean axis ratio did not contribute much to the high $Z_{\mathrm{DR}}$ with a large deviation (Fig. 11e), although the frequency of bulged particles increased more than that in the fast-falling group. Since the slow-falling group particles were still below the criteria of oscillating or tumbling in terms of the kinematic mechanism (blue dots in Fig. 12), other factors were considered to have caused the variety of fall orientations. Some of the previous reports revealed that there are other tumbling behaviors of ice particles when particles coagulate and completely freeze and become dry (Spengler and Gokhale 1972; Bringi and Chandrasekar 2001; Anderson et al. 2011; Ryzhkov et al. 2011). If this behavior can be triggered when freezing particles become dry, it coincides in timing with the mechanism of particle deceleration due to increasing the friction by drying of surfaces (Nicholls and Selberg 1968; Rasmussen and Heymsfield 1987). 

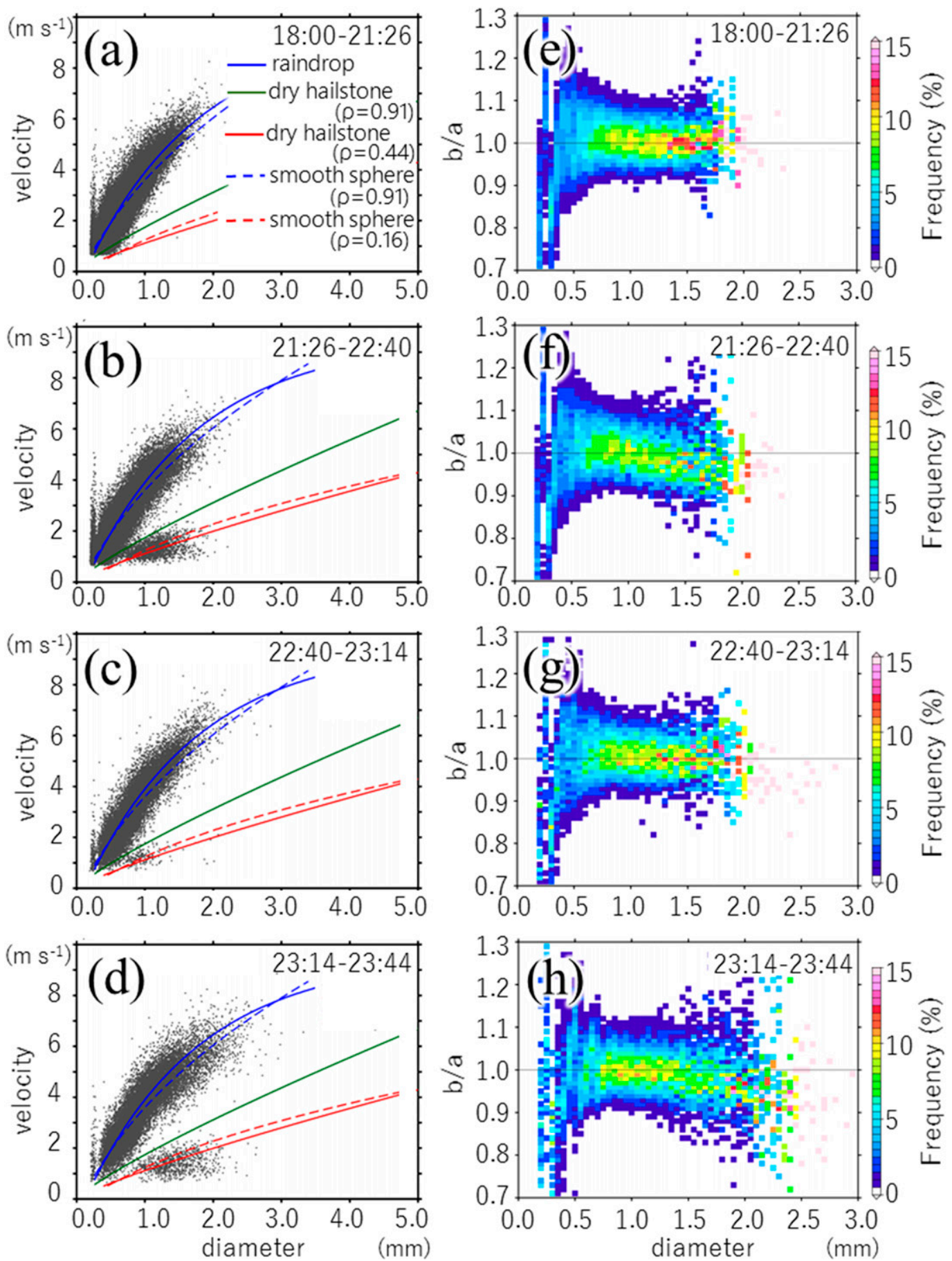

FIG. 8. (a)-(d) The hydrometeor fall velocities as a function of equivolumetric diameter collected by the 2DVD, which corresponds to the period in Fig. 5, with the terminal velocity lines of a raindrop (Atlas et al. 1973), dry hailstone for densities of 0.91 and $0.44 \mathrm{~g} \mathrm{~cm}^{-1}$ (Knight and Heymsfield 1983), and smooth spheres for densities of 0.91 and $0.16 \mathrm{~g} \mathrm{~cm}^{-1}$ (Mikhailov and Silva Freire 2013). (e)-(h) The normalized probability distributions of the axis ratio $(b / a)$ in each equivolumetric diameter bin (every $0.05 \mathrm{~mm}$ ). 


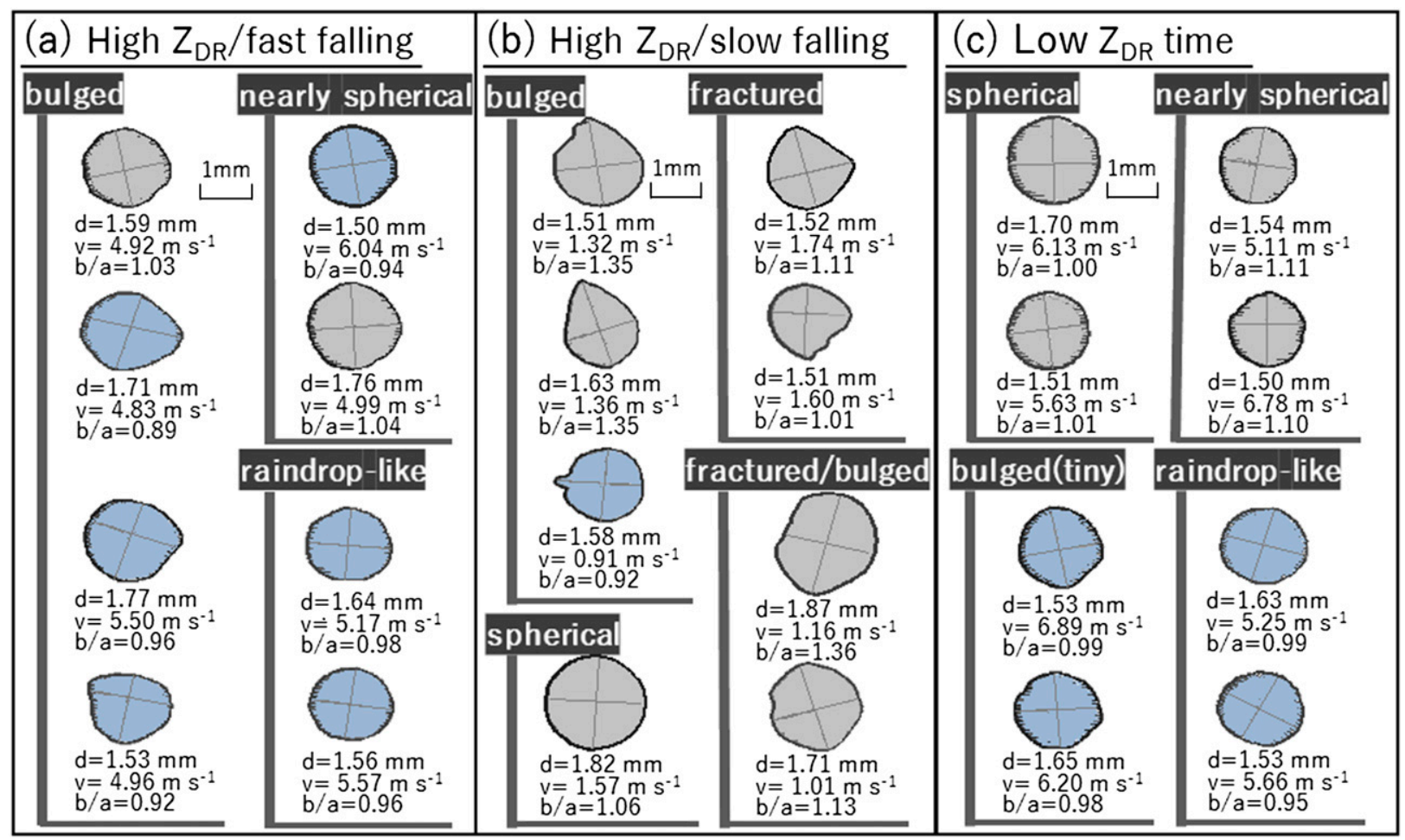

FIG. 9. The representative hydrometeor silhouettes over $1.5 \mathrm{~mm}$ in diameter monitored by the 2DVD at the MRI during the event. (a) Fastfalling particle group during the high $Z_{\mathrm{DR}}$ time, (b) slow-falling particle group during the high $Z_{\mathrm{DR}}$ time, and (c) hydrometeors during the low $Z_{\mathrm{DR}}$ time. The blue shade represents the particles with axis ratio lower than 1 . The gray shaded represents the others. The cross line in each particle image represents the longest line close to the zenithal direction and its perpendicular direction (the default setting in 2DVD imagers).

Dry conditions of ice particles generally occur when the latent heat of freezing is dissipated from particles while their temperature remains below $0^{\circ} \mathrm{C}$ (Ludlam 1958). Conversely, the ice particles with wet surfaces in subfreezing layer are suggestive of the stage of releasing of the latent heat of freezing (Yang and Good 1966). Considering the fact that almost all fractured silhouettes were observed in the slow-falling group at temperatures within $0^{\circ}-3^{\circ} \mathrm{C}$, it is possible that the latent heat of freezing had been sufficiently dissipated from the ice particles in the relatively cold subfreezing temperatures through reduction of the liquid water volume by ejection of the inner water. Hence, it can be also expected that a mean axis ratio slightly higher

TABLE 2. Number and frequency of occurrence of ice-pellet categories during the high $Z_{\mathrm{DR}}$ periods (fast-/slow-falling) and the low $Z_{\mathrm{DR}}$ periods on 29 Jan 2016. Boldface font indicates the top two categories in each case. The method of categories and computation are the same as those in Nagumo and Fujiyoshi (2015). The particles were categorized visually, and the total particle number in each period is less than the sum of the numbers in each category because some particles were placed in two or more categories.

\begin{tabular}{|c|c|c|c|c|c|c|}
\hline \multirow[b]{3}{*}{ Particle type } & \multirow{2}{*}{$\frac{\text { Low } Z_{\mathrm{DR}} 1800-2126 \mathrm{JST}}{-}$} & \multicolumn{2}{|c|}{$\begin{array}{c}\text { High } Z_{\mathrm{DR}} 2126-2240 \\
\text { JST }\end{array}$} & \multirow{3}{*}{$\frac{\frac{\text { Low } Z_{\mathrm{DR}} 2240-2314 \mathrm{JST}}{-}}{\text { No. }(\%)}$} & \multicolumn{2}{|c|}{$\begin{array}{c}\text { High } Z_{\mathrm{DR}} 2314-2344 \\
\text { JST }\end{array}$} \\
\hline & & Fast & Slow & & Fast & Slow \\
\hline & No. (\%) & No. (\%) & No. (\%) & & No. (\%) & No. (\%) \\
\hline Bulged & $61(13)$ & $176(29.3)$ & $113(72.4)$ & $42(5.9)$ & $683(37.8)$ & 217 (64.8) \\
\hline Spicule & $0(0)$ & $0(0)$ & $0(0)$ & $0(0)$ & $5(0.3)$ & $0(0)$ \\
\hline Fractured & $3(0.6)$ & $8(1.3)$ & $35(22.4)$ & $5(0.7)$ & $7(0.4)$ & 79 (23.6) \\
\hline Spherical & 83 (17.6) & $39(6.5)$ & $20(12.8)$ & $210(29.5)$ & $80(4.4)$ & $31(9.3)$ \\
\hline Nearly spherical & $293(62.2)$ & $327(54.5)$ & $15(9.6)$ & $406(57.0)$ & $797(43.9)$ & 64 (19.1) \\
\hline Irregular & $12(2.5)$ & $4(0.7)$ & $0(0)$ & $0(0)$ & $12(0.7)$ & $0(0)$ \\
\hline Aggregate/fused & $0(0)$ & $0(0)$ & $0(0)$ & $0(0)$ & $7(0.4)$ & $0(0)$ \\
\hline Raindrop-like & $19(4.0)$ & $70(11.7)$ & $0(0)$ & $49(6.9)$ & $221(12.2)$ & $0(0)$ \\
\hline Total number & 467 & 600 & 156 & 712 & 1817 & 335 \\
\hline
\end{tabular}


TABLE 3. Total number and frequency of occurrence of ice-pellet categories in the fast-falling group and slow-falling group ( $>1.5 \mathrm{~mm}$ in diameter) according to observations collected on 29 Jan 2016, and those reported by Nagumo and Fujiyoshi (2015). Boldface font indicates the top two categories in each case.

\begin{tabular}{|c|c|c|c|c|}
\hline \multirow[b]{3}{*}{ Particle type } & \multicolumn{2}{|c|}{ MRI event 29 Jan 2016} & \multicolumn{2}{|c|}{$\begin{array}{l}\text { Nagumo and Fujiyoshi (2015) } 10 \\
\text { Apr } 2005\end{array}$} \\
\hline & High $Z_{\mathrm{DR}} /$ Fast-falling & High $Z_{\mathrm{DR}} /$ Slow-falling & Fast-falling & Slow-falling \\
\hline & No. $(\%)$ & No. $(\%)$ & No. (\%) & No. (\%) \\
\hline Bulged & $863(35.7)$ & $330(67.2)$ & $4899(49.0)$ & $1492(62.0)$ \\
\hline Spicule & $5(0.2)$ & $0(0)$ & $80(0.8)$ & $31(1.3)$ \\
\hline Fractured & $15(0.6)$ & 114 (23.2) & $20(0.2)$ & $409(17.0)$ \\
\hline Spherical & $119(4.9)$ & $51(10.4)$ & $740(7.4)$ & $361(15.0)$ \\
\hline Nearly spherical & $1124(46.5)$ & $79(16.1)$ & $3999(40.0)$ & $99(4.1)$ \\
\hline Irregular & $16(0.7)$ & $0(0)$ & $20(0.2)$ & $7(0.3)$ \\
\hline Aggregate/fused & $7(0.3)$ & $0(0)$ & $150(1.5)$ & $43(1.8)$ \\
\hline Raindrop-like & $291(12.0)$ & $0(0)$ & $300(3.0)$ & $0(0)$ \\
\hline Total number & 2417 & 491 & 9998 & 2407 \\
\hline
\end{tabular}

than 1 in the slow-falling group is explained by the nonhomogeneity of ice and air in the particles, which can cause a mismatch between the positions of the centers of particles and positions of the centers of gravity. Since ice particles that are dry have a lower dielectric constant than that of liquid, this does not contradict the phenomena observed during the high $Z_{\mathrm{DR}}$ periods.

\section{b. Freezing process throughout the geometrical changes}

The compositions of hydrometeors during the low $Z_{\mathrm{DR}}$ periods with spherical shapes were investigated by comparing the data with theoretical axis ratios of raindrops in terms of their surface tension under different environments. The axis ratios of raindrops at steady state according to Green (1975) can be represented as shown in the following function:

$$
r=\left[\left(\frac{4}{17}\right)\left(\frac{17}{4} B+1\right)^{1 / 2}+\frac{13}{17}\right]^{-3 / 2} .
$$

Here, the axis ratio $r$ is expressed by coefficient $B$, which is a function of the atmospheric density $\rho_{a}$, gravity acceleration $g$, raindrop diameter $d$, and surface tension $\sigma$, and it can be expressed as follows:
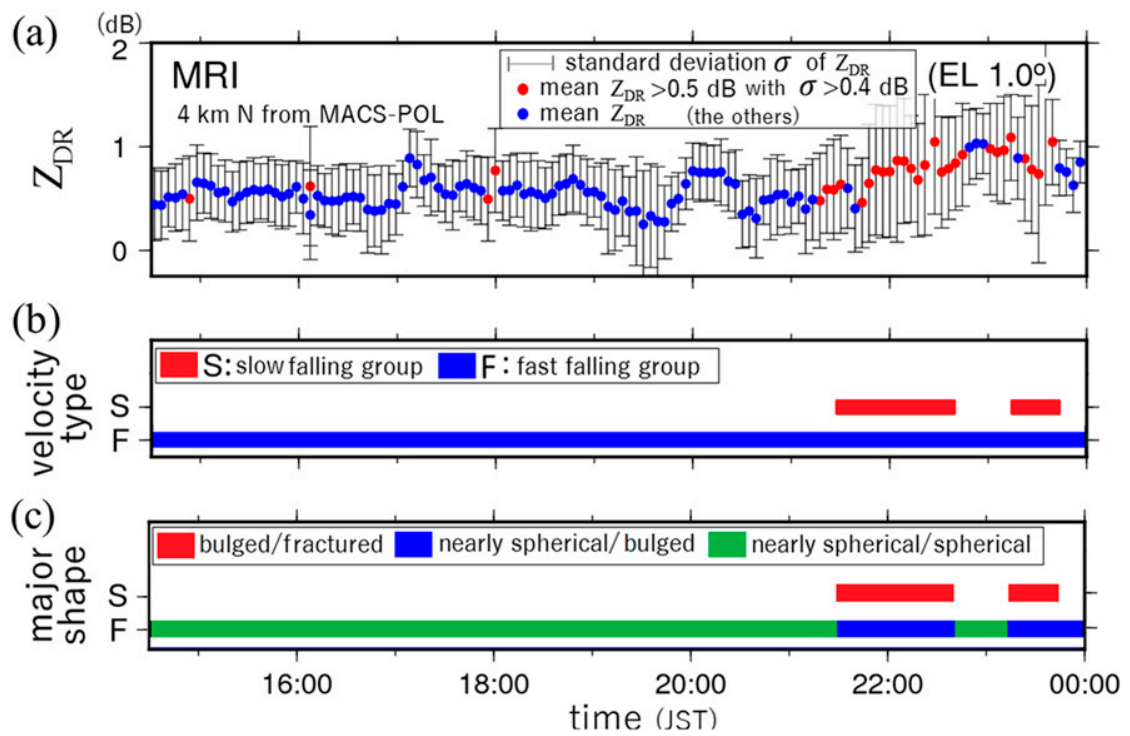

FIG. 10. (a) Time series of the $Z_{\mathrm{DR}}$, standard deviation of $Z_{\mathrm{DR}}$, and hydrometeor types over the observatories at the MRI, (b) hydrometeor fall velocity types by the 2DVD, and (c) major two shape categories broken down by $Z_{\mathrm{DR}}$ signals in (a) and fall velocity type in (b). The mean $Z_{\mathrm{DR}}$ represents the results from a $4-\mathrm{km}$ square area over a region located $4 \mathrm{~km}$ north of the MRI. 

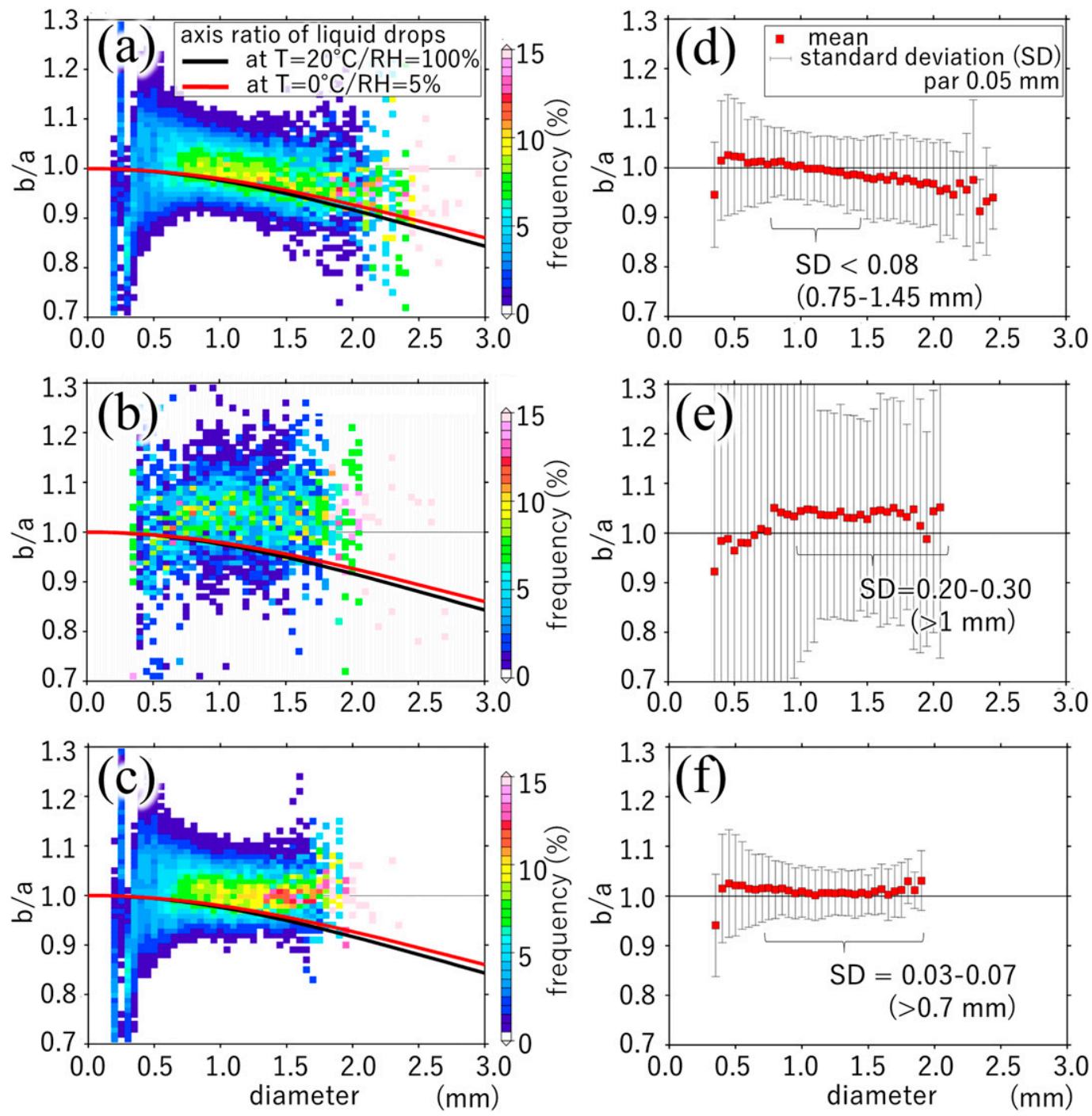

FIG. 11. The normalized probability distributions of axis ratios $(b / a)$ in each diameter bin (every $0.05 \mathrm{~mm})$ broken down by time and fall velocity: (a) fast-falling group, high $Z_{\mathrm{DR}}$ periods (2127-2240/2314-2344 JST), (b) slow-falling group, high $Z_{\mathrm{DR}}$ time [same time as (a)], and (c) low $Z_{\mathrm{DR}}$ time (1800-2100 JST) with the theoretical line of the raindrop axis ratio depending on the temperature $\left({ }^{\circ} \mathrm{C}\right)$ and relative humidity $(\%)$. Black lines indicate the condition at $20^{\circ} \mathrm{C}$, $100 \%$ conditions, and red lines indicate the condition at $0{ }^{\circ} \mathrm{C}, 5 \%$. The distribution of the mean and standard deviation of axis ratios in each diameter bin: (d) same period as (a), (e) same period as (a), and (f) same period as (c).

$$
B=\frac{\rho_{a} g d^{2}}{4 \sigma}
$$

Since $\rho_{a}$ and $g$ hardly change near the ground surface, Eq. (1) is considered to be a curvature function related to the diameter and surface tension. The surface tension is an environment-dependent parameter related to the temperature $\left({ }^{\circ} \mathrm{C}\right)$ and relative humidity (\%). Liquid water under lower temperature and lower relative humidity environments will show a higher surface tension (e.g., Pérez-Díaz et al. 2017). The theoretical curvatures of raindrop axis ratios within the realistic environment are composited in Figs. 11a-c with the probability distributions of observed axis ratios from 2DVD images (black line: $20^{\circ} \mathrm{C}, 100 \%$, and red line: $0^{\circ} \mathrm{C}, 5 \%$ ). These results suggest that the effects of surface tension hardly contributed to the axis ratios, and almost all of the hydrometeors contained at least some ice on their surfaces.

A spherical ice particle generally occurs at the initial stage of freezing process associated with a volume change from water to ice, and then, the particle forms a singularity point like a bulge in the next stage (Snoeijer and Philippe 2012; Marín et al. 2014). If this evolution of geometry is the initial stage of freezing, the suggested 


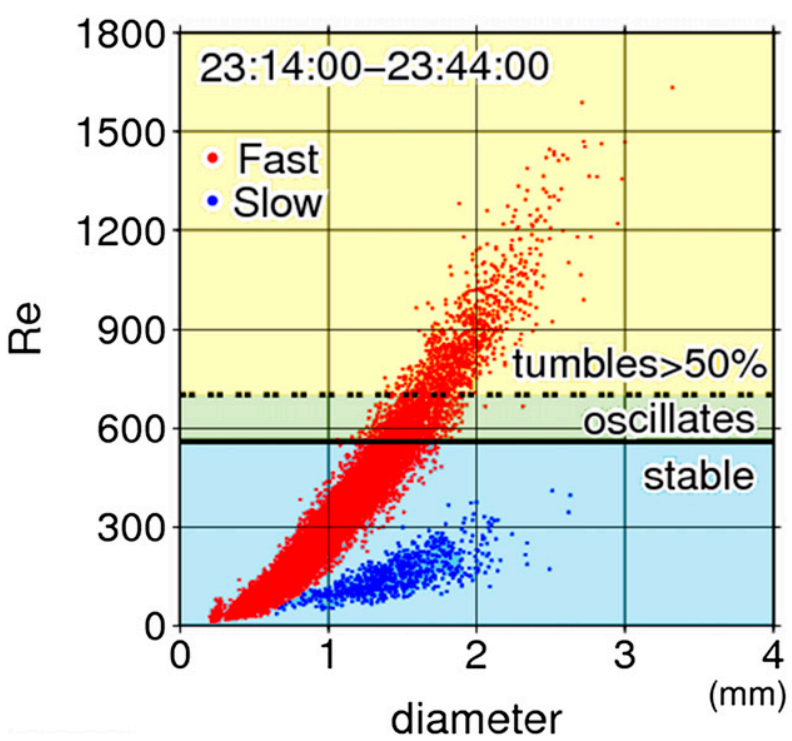

FIG. 12. The diameter-Reynolds number ( $\mathrm{Re})$ relations. The red dots depict the fast-falling hydrometeors, and blue dots depict the slow-falling hydrometeors. The upper area (yellow), middle area (green), and lower area (blue) signify the behavior of teardropshape particles corresponding to the Reynolds number based on List and Schemenauer (1971).

mechanism of fast-falling velocities caused by wet surfaces does not conflict. This is because the initial stage of freezing is likely related to the phase of release of latent heat in the relatively warm subfreezing temperatures. As deformation progresses with the further freezing, the low $Z_{\mathrm{DR}}$ periods can be considered to be a preceding stage of high $Z_{\mathrm{DR}}$ periods. In contrast, the low $Z_{\mathrm{DR}}$ periods with rain or rain/ice-pellet mixtures are not considered to be a stage of melting near the surface, which is because during the melting stage, ice particles are surrounded by an oblate coat of water and show relatively high $Z_{\mathrm{DR}}$ values $(>1.0 \mathrm{~dB}$ ) (Rasmussen and Heymsfield 1987; Höller et al. 1994).

\section{c. Conceptual model of the geometry of ice pellets}

As evident from the preceding sections, complicated precipitation characteristics occur during the freezing process. The basic concept of the freezing process of ice pellets is that raindrops turn to solid ice particles, but this is insufficient for considering the microphysics in correspondence with dual-polarization signals. While the development of precipitation subjected to different processes in winter storms and subsequent ice-pellet formation in terms of the classification of the geometry has been summarized by Stewart and Crawford (1995), the relation between microphysical characteristics and ice-pellet type evolution has not been adequately discussed.
By incorporating many of the now-known processes and new findings, a conceptual model can account for the dual-polarization signals of $Z_{\mathrm{DR}}$ observed during the freezing process. Figure 13 shows the possible temporal evolution of geometrical characteristics of hydrometeors and corresponding radar-based characteristics in association with a refreezing process. The high $Z_{\mathrm{DR}}$ layer including many long sideways-oriented ice pellets is evident between the prior spherical geometries of initial freezing particles and the subsequent isotropic or vertically long geometries on average with various orientations of deformed ice pellets (e.g., bulged or fractured ones). The suggestion that the ice pellets with dry surfaces are partly produced from the ice pellets with wet surfaces via evolution of deformations in the high $Z_{\mathrm{DR}}$ layer is consistent with the fact that the $\rho_{\mathrm{hv}}$ decreases in the subfreezing layer occurred below the high $Z_{\mathrm{DR}}$ peak. Then, the final stage of geometrical characteristics of ice pellets have low values of $Z_{\mathrm{DR}}(\sim 0 \mathrm{~dB}$ or negative) due to the disappearance of wet ice pellets as in the case of Kumjian et al. (2013).

\section{Conclusions}

An ice-pellet event occurred on 29 January 2016, in the north Kanto Plain, Japan, together with freezing rain over the vicinity of the mountainous region. The dualpolarization radar observations indicated a locally high $Z_{\mathrm{DR}}$ layer as well as locally low $\rho_{\mathrm{hv}}$ when the structure had a subfreezing layer beneath the melting layer. Such polarimetric features showed good agreement with the duration of ice-pellet reports. The value of $Z_{\mathrm{DR}}$ was $>0.5 \mathrm{~dB}$ in terms of the mean and $>0.4 \mathrm{~dB}$ in terms of the standard deviation during this event. The 2DVD observations indicated the simultaneous presence of ice pellets with a bimodal terminal velocity distribution (e.g., fast- and slow-falling velocity groups) during the high $Z_{\mathrm{DR}}$ periods. The 2DVD observations of geometrical properties also revealed a consistency with the high $Z_{\mathrm{DR}}$ signals in terms of geometrical change with the majority consisting of long sideways-falling orientations (e.g., bulged, nearly spherical, and fractured ice pellets). On the other hand, many of the 2DVD observations during the low $Z_{\mathrm{DR}}$ period showed consistency in terms of spherical axis ratios, but inconsistency in terms of one terminal velocity distribution close to that of raindrops; also, the major reports indicated there were rain or rain/ ice-pellet mixtures.

The detailed investigation of the geometry of hydrometeors during the high $Z_{\mathrm{DR}}$ period indicated that fall orientations of the fast-falling group had lower axis ratios with increasing diameters. A number of particles showing deformation (e.g., bulged and nearly spherical 


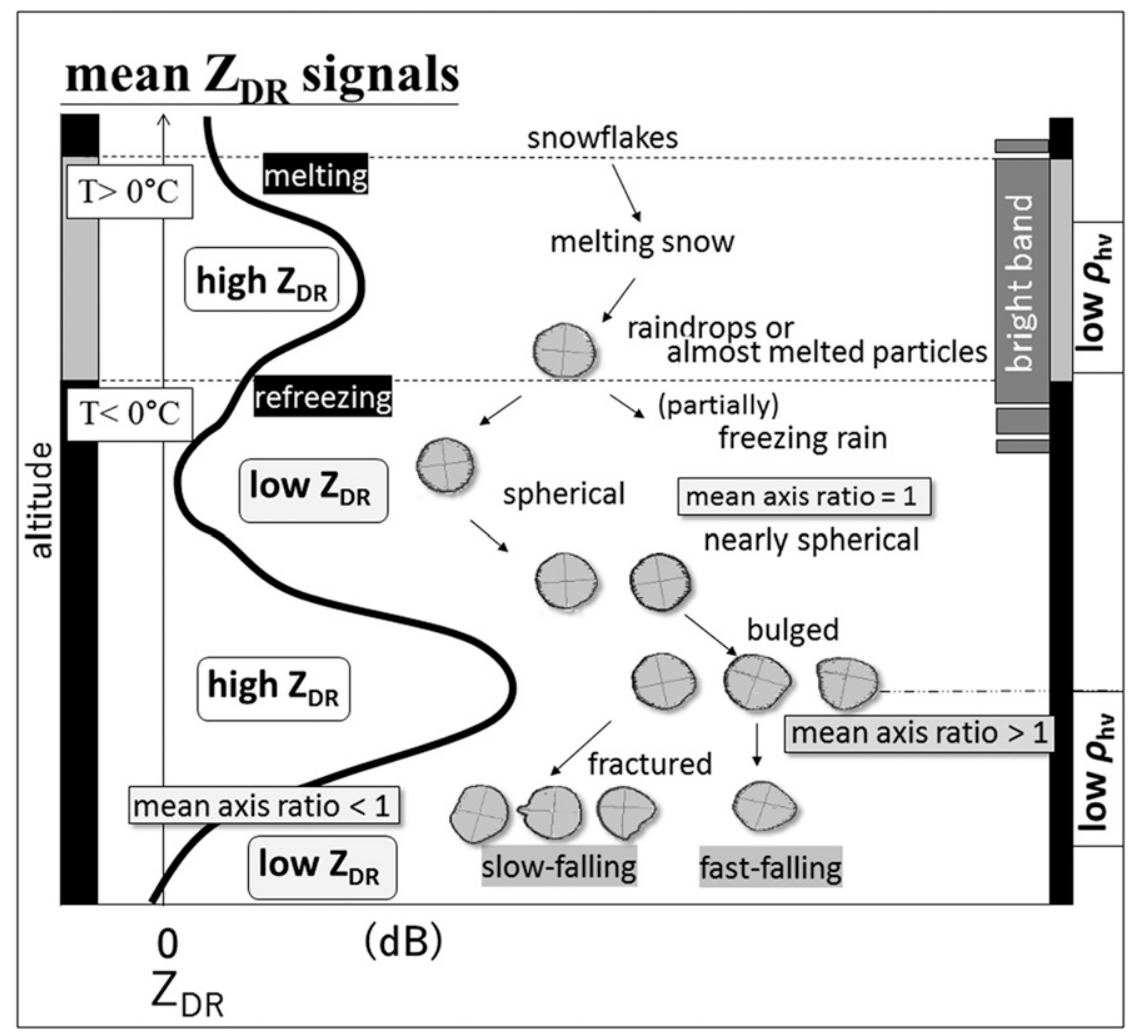

FIG. 13. Schematic diagram of the mean $Z_{\mathrm{DR}}$ signals and some of the geometrical characteristics in the case of winter storms in association with a refreezing process including a high $Z_{\mathrm{DR}}$ peak in the subfreezing layer from high melting rate of particles. Black bars indicate the subfreezing layer, and gray bars indicate the warm layer above $0^{\circ} \mathrm{C}$.

ice pellets) and stable falling orientations in the fastfalling group were found to be important for the high $Z_{\mathrm{DR}}$ during the ice-pellet event. The fall orientations of the slow-falling group were rather in various directions with a high frequency of deformed particles (e.g., bulged and fractured particles), and this resulted in axis ratios near 1 or greater than 1 in terms of mean. The source of the various directions of particles has been suggested to be a tumbling motion that is promoted when freezing particles become dry (Spengler and Gokhale 1972; Bringi and Chandrasekar 2001; Anderson et al. 2011; Ryzhkov et al. 2011). The slow-falling mode of velocity also suggests the characteristics of ice pellets with dry surfaces. Hence, this group of microphysics and radar signals in terms of the $Z_{\mathrm{DR}}$ is rather fit into the general concept of completely freezing stage of ice particles, in contrast to the semifreezing condition with wet and fastfalling mode of hydrometeors.

Further investigations of the geometry of hydrometeors during the low $Z_{\mathrm{DR}}$ period indicated that the almost all of the particles were freezing ice spheres from the viewpoints of the surface tension of liquid particles. Assuming liquid drops, the axis ratios of falling liquid drops in steady state show lower axis ratios with increasing diameters even with general surface tension and high surface tension (the colder and drier conditions). A spherical shape has been suggested to form prior to partial deformation during the freezing process due to internal volume expansion from the outside inward. The suggestion that the spherical particles were in the initial stage of freezing is consistent with the findings of their falling velocity being close to that of raindrops. The freezing particles release latent heat from the surface at first and present wet surfaces in slight supercooled conditions. As a result, visual observation reports were considered to be rain or rain/ice-pellet mixtures during the low $Z_{\mathrm{DR}}$ periods.

This paper presents a conceptual model on the geometrical properties from completely melted snowflakes to just before the final stage of refreezing, and the dualpolarization signals of $Z_{\mathrm{DR}}$ showed low $Z_{\mathrm{DR}}$ and high $Z_{\mathrm{DR}}$ values between the freezing of raindrops and the deformation of ice particles. The high $Z_{\mathrm{DR}}$ layer with long sideways-oriented freezing particles is clearly evident between the periods of low $Z_{\mathrm{DR}}$ associated with spherical freezing particles and deformed frozen particles 
with various directions of orientation. Our next research task will involve the identification of universal microphysical mechanisms for the geometrical properties including those of refreezing of semimelted snowflakes and their auto detection by using dual-polarization radar.

Acknowledgments. This study was partially supported by JSPS KAKENHI Grants $15 \mathrm{~K} 01273$ and $17 \mathrm{H} 00852$. We are grateful to the personnel of the Observation Division of the Japan Meteorological Agency for their valuable comments. We would also like to thank Mr. Hiroaki Kawase for providing an ice-pellet picture of this event. The temperature data were obtained from the Mt. Tsukuba project operated by the University of Tsukuba. The comments by Mr. Yoshinori Shoji, senior researcher of MRI, and Prof. Yasushi Fujiyoshi are greatly acknowledged. Finally, we are grateful to the reviewers and editors.

\section{REFERENCES}

Adachi, A., T. Kobayashi, H. Yamauchi, and S. Onogi, 2013: Detection of potentially hazardous convective clouds with a dualpolarized C-band radar. Atmos. Meas. Tech., 6, 2741-2760, https://doi.org/10.5194/amt-6-2741-2013.

Anderson, M. E., L. D. Carey, W. A. Petersen, and K. R. Knupp, 2011: C-band dual-polarimetric radar signatures of hail. Electron. J. Oper. Meteor., 12 (2), 1-30.

Atlas, D., R. C. Srivastava, and R. S. Sekhon, 1973: Doppler radar characteristics of precipitation at vertical incidence. Rev. Geophys. Space Phys., 11, 1-35, https://doi.org/10.1029/ RG011i001p00001.

Baldini, L., and E. Gorgucchi, 2006: Identification of the melting layer through dual-polarization radar measurements at vertical incidence. J. Atmos. Oceanic Technol., 23, 829-839, https:// doi.org/10.1175/JTECH1884.1.

Bigg, E. K., 1953: The formation of atmospheric ice crystals by the freezing of droplets. Quart. J. Roy. Meteor. Soc., 79, 510-519, https://doi.org/10.1002/qj.49707934207.

Blanchard, D. C., 1957: The supercooling, freezing and melting of giant waterdrops at terminal velocity in air. Artificial Stimulation of Rain, H. Weickmann and W. Smith, Eds., Pergamon Press, 233-245.

Brandes, E. A., and K. Ikeda, 2004: Freezing-level estimation with polarimetric radar. J. Appl. Meteor., 43, 1541-1553, https://doi.org/10.1175/JAM2155.1.

Bringi, V. N., and V. Chandrasekar, 2001: Polarimetric Doppler Weather Radar: Principles and Applications. Cambridge University Press, $636 \mathrm{pp}$.

Brooks, C., 1920: The nature of sleet and how it is formed. Mon. Wea. Rev., 48, 69-72, https://doi.org/10.1175/1520-0493(1920) $48<69$ b:TNOSAH $>2.0 . \mathrm{CO} ; 2$.

Cortinas, J. V., Jr., B. C. Bernstein, C. C. Robbins, and J. W. Strapp, 2004: An analysis of freezing rain, freezing drizzle, and ice pellets across the United States and Canada: 1976-90. Wea. Forecasting, 19, 377-390, https://doi.org/10.1175/1520-0434(2004) 019<0377:AAOFRF $>2.0 . \mathrm{CO} ; 2$.

Crawford, R. W., and R. E. Stewart, 1995: Precipitation type characteristics at the surface in winter storms. Cold Reg. Sci.
Technol., 23, 215-229, https://doi.org/10.1016/0165-232X(94) 00014-O.

Dorsey, N. E., 1948: The freezing of supercooled water. Trans. Amer. Philos. Soc., 38, 247-328, https://doi.org/10.2307/ 1005602.

Edwards, G. R., and L. F. Evans, 1971: Mechanism of activation of ice nuclei. J. Atmos. Sci., 28, 1443-1447, https://doi.org/ 10.1175/1520-0469(1971)028<1443:TMOAOI $>2.0 . C O ; 2$.

Gibson, S., and R. E. Stewart, 2007: Observations of ice pellets during a winter storm. Atmos. Res., 85, 64-76, https://doi.org/ 10.1016/j.atmosres.2006.11.004.

,-- , and W. Henson, 2009: On the variation of ice pellet characteristics. J. Geophys. Res., 114, D09207, https://doi.org/ 10.1029/2008JD011260.

Gokhale, N. R., and O. Lewinter, 1971: Microcinematographic studies of contact nucleation. J. Appl. Meteor., 10, 469-473, https:// doi.org/10.1175/1520-0450(1971)010<0469:MSOCN >2.0.CO;2.

Green, A. W., 1975: An approximation for the shapes of large raindrops. J. Appl. Meteor., 14, 1578-1583, https://doi.org/ 10.1175/1520-0450(1975)014<1578:AAFTSO > 2.0.CO;2.

Höller, H., V. N. Bringi, J. Hubbert, M. Hagen, and P. F. Meischner, 1994: Life cycle and precipitation formation in a hybrid-type hailstorm revealed by polarimetric and Doppler radar measurements. J. Atmos. Sci., 51, 2500-2522, https://doi.org/10.1175/ 1520-0469(1994)051<2500:LCAPFI >2.0.CO;2.

Joseph, N., and C. Will, 2015: Contact freezing of water by salts. J. Phys. Chem. Lett., 6, 2390-3495.

Knight, C. A., and A. J. Heymsfield, 1983: Measurement and interpretation of hailstone density and terminal velocity. J. Atmos. Sci., 40, 1510-1516, https://doi.org/10.1175/15200469(1983)040<1510:MAIOHD>2.0.CO;2.

Kumjian, M. R., A. V. Ryzhkov, J. D. Reeves, and T. J. Schuur, 2013: A dual-polarization radar signature of hydrometeor refreezing in winter storms. J. Appl. Meteor. Climatol., 52, 25492566, https://doi.org/10.1175/JAMC-D-12-0311.1.

List, R., and R. S. Schemenauer, 1971: Free-fall behavior of planar snow crystals, conical graupel and small hail. J. Atmos. Sci., 28, 110-115, https://doi.org/10.1175/1520-0469(1971)028<0110: FFBOPS $>2.0 . \mathrm{CO} ; 2$.

Ludlam, F. H., 1958: The hail problem. Nublia, 1, 12-99.

Marín, A. G., O. R. Enríquez, P. Brunet, P. Colinet, and J. H. Snoeijer, 2014: Universality of tip singularity formation in freezing water drops. Phys. Rev. Lett., 113, 1-5, https://doi.org/ 10.1103/PhysRevLett.113.054301.

Mikhailov, M. D., and A. P. Silva Freire, 2013: The drag coefficient of a sphere: An approximation using Shanks transform. Powder Technol., 237, 432-435, https://doi.org/ 10.1016/j.powtec.2012.12.033.

Mossop, S. C., R. E. Ruskin, and K. J. Heffernan, 1968: Glaciation of a cumulus at approximately $-4^{\circ}$ C. J. Atmos. Sci., 25, 889-905, https://doi.org/10.1175/1520-0469(1968)025<0889: GOACAA $>2.0 . \mathrm{CO} ; 2$.

Nagumo, N., and Y. Fujiyoshi, 2015: Microphysical properties of slow-falling and fast-falling ice pellets formed by freezing associated with evaporative cooling. Mon. Wea. Rev., 143, 43764392, https://doi.org/10.1175/MWR-D-15-0054.1.

Nicholls, J. A., and B. P. Selberg, 1968: Drag coefficient of small spherical particles. AIAA J., 6, 401-408, https://doi.org/ 10.2514/3.4513.

Pérez-Díaz, J. L., and Coauthors, 2017: Fogs: Physical basis, characteristic properties, and impact on the environment and human health. Water, 9, 807, https://doi.org/10.3390/ w9100807. 
Poiares Baptista, J. V. P., 1992: Minute of radar working group. Proc. Olympus Propagation Experimenters'17, Stockholm, Sweden/Helsinki, Finland, NASA, 36-40.

Pruppacher, H. R., and K. V. Beard, 1970: A wind tunnel investigation of the internal circulation and shape of water drops falling at terminal velocity in air. Quart. J. Roy. Meteor. Soc., 96, 247-256, https://doi.org/10.1002/qj.49709640807.

—_, and J. D. Klett, 1997: Microphysics of Clouds and Precipitation. Kluwer Academic Publishers, 954 pp.

Rasmussen, R. M., and A. J. Heymsfield, 1987: Melting and shedding of graupel and hail. Part I: Model physics. J. Atmos. Sci., 44, 2754-2763, https://doi.org/10.1175/1520-0469(1987) 044<2754:MASOGA $>2.0$.CO;2.

Ressler, G. M., S. M. Milrad, E. H. Atallah, and J. R. Gyakum, 2012: Synoptic-scale analysis of freezing rain events in Montreal, Quebec, Canada. Wea. Forecasting, 27, 362-378, https:// doi.org/10.1175/WAF-D-11-00071.1.

Ryzhkov, A. V., H. D. Reeves, T. J. Schuur, M. R. Kumjian, and D. S. Zrnić, 2011: Investigations of polarimetric radar signatures in winter storms and their relation to aircraft icing and freezing rain. 35th Conf. on Radar Meteorology, Pittsburgh, PA, Amer. Meteor. Soc., P13.197, https://ams.confex.com/ ams/35Radar/webprogram/Paper191245.html.

Sassen, K., P. J. DeMott, J. M. Prospero, and M. R. Poellot, 2003: Saharan dust storms and indirect aerosol effects on clouds: CRYSTAL-FACE results. Geophys. Res. Lett., 30, 1633, https://doi.org/10.1029/2003GL017371.

Schönhuber, M., G. Lammer, and W. L. Randeu, 2007: One decade of imaging precipitation measurement by $2 \mathrm{D}$-video-disdrometer. Adv. Geosci., 10, 85-90, https://doi.org/10.5194/adgeo-10-85-2007.

,-- , and - 2008: The 2D-videodisdrometer. Precipitation: Advances in Measurement, Estimation and Prediction, S. Michaelides, Ed., Springer, 3-31.
Snoeijer, J. H., and B. Philippe, 2012: Pointy ice-drops: How water freezes into a singular shape. Amer. J. Phys., 80, 764-771, https://doi.org/10.1119/1.4726201.

Spengler, J. D., and N. R. Gokhale, 1972: Freezing of freely suspended supercooled water drops in a large vertical wind tunnel. J. Appl. Meteor., 11, 1101-1107, https://doi.org/10.1175/ 1520-0450(1972)011<1101:FOFSSW > 2.0.CO;2.

Stewart, R. E., and R. W. Crawford, 1995: Some characteristics of the precipitation formed within winter storms over eastern Newfoundland. Atmos. Res., 36, 17-37, https://doi.org/10.1016/ 0169-8095(94)00004-W.

Takahashi, C., 1975: Deformation of frozen drops and their frequencies. J. Meteor. Soc. Japan, 53, 402-411, https://doi.org/ 10.2151/jmsj1965.53.6_402.

_ supercooled cloud. J. Meteor. Soc. Japan, 48, 373-376, https:// doi.org/10.2151/jmsj1965.48.4_373.

Thompson, E. J., S. A. Rutledge, B. Dolan, V. Chandrasekar, and B. L. Cheong, 2014: A dual-polarization radar hydrometeor classification algorithm for winter precipitation. J. Atmos. Oceanic Technol., 31, 1457-1481, https://doi.org/10.1175/ JTECH-D-13-00119.1.

Thurai, M., and V. N. Bringi, 2005: Drop axis ratios from a 2D video distrometer. J. Atmos. Oceanic Technol., 22, 966-978, https://doi.org/10.1175/JTECH1767.1.

Yang, L. C., and W. B. Good, 1966: Crystallization rate of supercooled water in cylindrical tubes. J. Geophys. Res., 71, 24652469, https://doi.org/10.1029/JZ071i010p02465.

Zrnić, D. S., N. Balakrishnan, C. L. Ziegler, V. N. Bringi, K. Aydin, and T. Matejka, 1993: Polarimetric signatures in the stratiform region of a mesoscale convective system. J. Appl. Meteor., 32, 678-693, https://doi.org/10.1175/1520-0450(1993)032<0678: PSITSR $>2.0 . \mathrm{CO} ; 2$. 